\title{
Beyond BlackBerry thumb
}

$\mathrm{S}$ o long BlackBerry thumb. Hello, i-Pad finger. Ergonomic experts are predicting that a new generation of hand injuries may be in the offing as a result of the trend toward touch screen versions of smartphones, tablets and other technologies which involve more one-finger typing and swiping of the thumb than simply typing with the thumbs.

But industrial experts say they're moving to design user interfaces that will reduce the stress related to extensive use of the fingers as a result of having round-the-clock wireless access to the world.

Even Research in Motion (RIM), the Canadian firm that led the smartphone revolution with its award-winning BlackBerry product line, says it's taking such ergonomic considerations into its designs and plans to soon unveil a model that will include both a full touch screen, as well as a half touch/half keypad option.

Complaints about repetitive strain injuries prompted by excessive use of BlackBerrys and other mobile devices have become so common that a simple Google search of the words "treatment BlackBerry thumb" returns 3.17 million results. Treatments range from ice to surgery.

But as the world of electronic gadgets evolves and more Canadians purchase newer models of smartphones, tablets, ereaders and other manner of mobile devices, some experts believe a new generation of injuries will also emerge.

The use of touch screens may itself increase risk of injury, notes Dr. Franklin Tessler, professor in the Department of Radiology at the University of Alabama at Birmingham. Although many touch screen devices allow for haptic (touch) feedback when keys are touched, that feature is typically disabled and "what tends to happen when you're not sure whether you've actually actuated the key or not, and this happens with virtual keyboards that are purely on the screen, is that you tend to press harder. ... The harder you press, the more force you

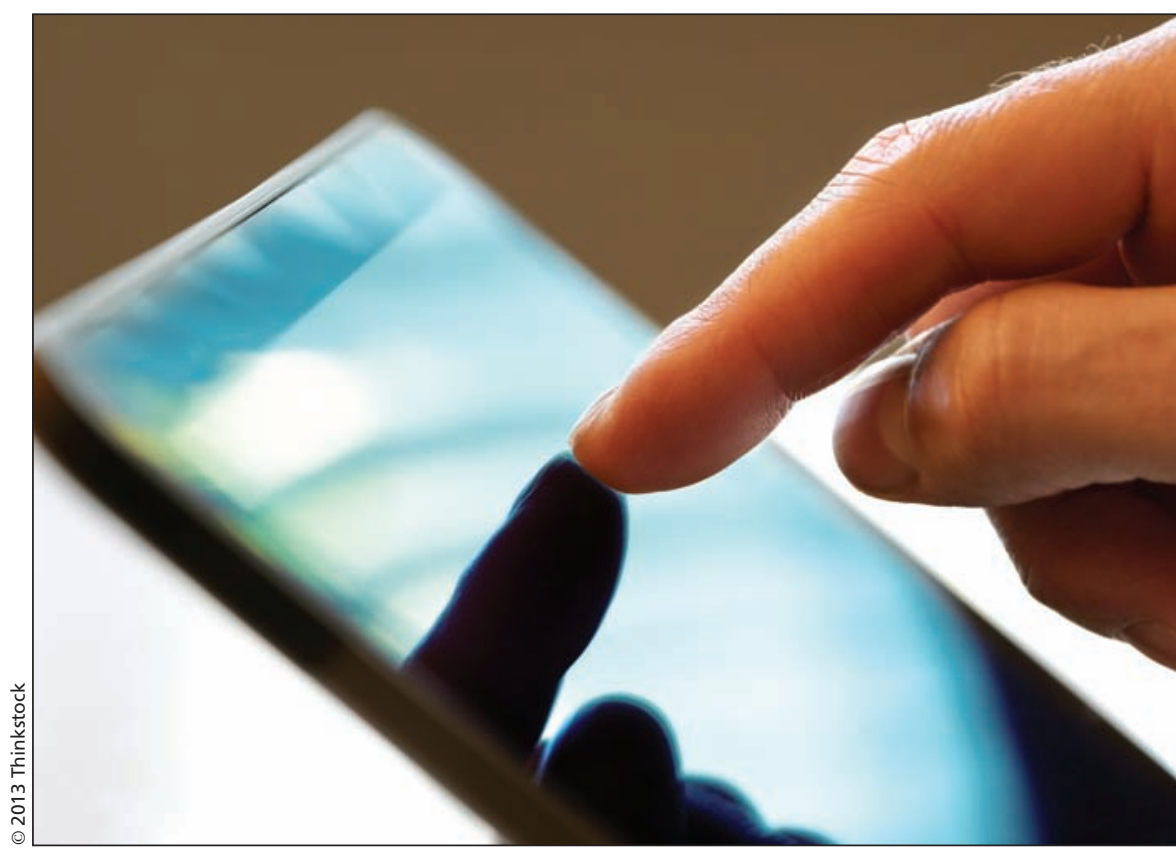

Touch screen devices tend to be used with one hand, which can lead to more fatigue in a finger or thumb, because it is required to work harder.

exert in these small motions, and the more risk of injury."

Others say that the one-finger typing or swiping motions that are typically associated with touch screen technologies could potentially lead to injury.

"If you text using both hands, you're distributing the load across two thumbs whereas if you're using the one-handed technique you're doubling the load to that individual finger rather than distributing between two fingers," says Peter Johnson, associate professor in the Department of Environmental and Occupational Health Sciences at the University of Washington in Seattle.

Touch screen devices tend to be used with one hand, which can lead to more fatigue in a finger or thumb, because it is required to work harder, he adds.

The diminutive size and proximity of keys on touch screen devices are also a concern as they can lead to increased use, Tessler notes. Users will likely have to make more corrections and thus utilize motions that involve more stress on the hands, he adds. "It's obviously easier to do a repetitive motion if you're not very intent on hitting a very small target.'

Several experts say many of the potential problems can be averted if user interfaces are designed to minimize such stressors.

That's one of the aims of touch screen devices, argues Joseph Hofer, senior industrial designer at RIM. They actually reduce fatigue and strain because there is no requirement that a user physically press a button, he says, adding that the smooth glass screen may reduce effort if keys are touched gently and precisely.

Tessler says the evolution of other capabilities, such as voice to text software, which will allow users to communicate on their devices without overuse of their thumbs, should also help to reduce injury.

Use of the auto-correct function on mobile devices is another means of reducing the risk of repetitive strain injury, Hofer says. To that end, the next generation BlackBerry will have the function built-in. "As you're typing it's predicting what the next word might 
be. It places these suggested words above letters that your eyes would naturally be headed towards," he says.

Tessler says that users should also consider switching to other keypad layouts that are now possible in the latest devices.

But the risks of excessive use of touch screen devices aren't limited to the hands, Johnson says, noting that unnatural postures while holding the devices up in the air could lead to shoulder injuries.

Tessler says that taking frequent breaks and knowing one's limitations are the main methods of avoiding repet- itive strain injuries. "There's a misconception out there that if some activity is causing pain, if you just keep it up, it will get better. Pain is your body's way of telling you that you shouldn't be doing something, not that you should do more of it."

Yet while the experts predict that the next generation of mobile devices will present its own series of health challenges, and likely an equivalent to BlackBerry thumb, they say there's no way to ascertain the extent to which the degree of health risk will be elevated.

Young people who text frequently will provide a true measure whether extended use of touch screen devices poses a great threat of injury, says Johnson, who's also worried about the longterm psychological and physiological risk involved with extensive and excessive mobile device use. "There are people that were introduced to this device in their teenage years and they will be intensive texters for a long time," he says. "Maybe once they hit their twenties or thirties we might see some cumulative outcomes from all this intensive texting. We're on the front end of the wave." Bonnie O'Sullivan, Ottawa, Ont.

CMAJ 2013. DOI:10.1503/cmaj.109-4395 